Quim. Nova, Vol. 32, No. 5, 1144-1150, 2009

\title{
INFLUÊNCIA DA AÇÃO DAS ENZIMAS ALCALASE E FLAVOURZYME NO GRAU DE HIDRÓLISE DAS PROTEÍNAS DE CARNE DE FRANGO
}

\author{
Cristiano Gautério Schmidt e Myriam Salas-Mellado* \\ Escola de Química de Alimentos, Universidade Federal do Rio Grande, CP 474, 96201-900 Rio Grande - RS, Brasil
}

Recebido em 15/4/08; aceito em 12/1/09; publicado na web em 11/5/09

\begin{abstract}
INFLUENCE OF ALCALASE AND FLAVOURZYME PERFORMANCE ON THE DEGREE OF HYDROLYSIS OF THE PROTEINS OF CHICKEN MEAT. To study the action of Alcalase and Flavourzyme on the proteins of chicken meat, the influence of the substrate concentration [S], enzyme concentration [E] and hydrolysis time on the degree of hydrolysis (DH) of the proteins was evaluated. The highest DH for breast meat was obtained with a $[\mathrm{S}]$ of $3.3 \%(\mathrm{w} / \mathrm{v})$, with a $[\mathrm{E}]$ of $6 \%(\mathrm{w} / \mathrm{w})$ and reaction time of $90 \mathrm{~min}$, for both enzymes. For thigh meat the conditions to get the highest DH were: $[\mathrm{S}]$ of $5 \%(\mathrm{w} / \mathrm{v}),[\mathrm{E}]$ of $8 \%(\mathrm{w} / \mathrm{w})$ and a reaction time of $120 \mathrm{~min}$, for both enzymes.
\end{abstract}

Keywords: chicken, hydrolysates, proteases.

\section{INTRODUÇÃO}

A alta complexidade das moléculas de proteínas provavelmente é a principal responsável pelo pouco conhecimento das transformações químicas a que as mesmas estão sujeitas no processamento e armazenamento dos alimentos. ${ }^{1}$

A modificação enzimática das proteínas utilizando enzimas proteolíticas selecionadas para cindir ligações peptídicas específicas é amplamente utilizada na indústria de alimentos. ${ }^{2} \mathrm{~A}$ adição de enzimas para hidrolisar as proteínas dos alimentos é um método reconhecido por melhorar ou modificar as propriedades físico-químicas, funcionais e sensoriais das proteínas iniciais, sem prejudicar o seu valor nutritivo. ${ }^{3}$ As enzimas utilizadas nas indústrias de alimentos e nas pesquisas cientificas, predominantemente, são hidrolases, a maioria carboidratases, seguidas das proteases e lípases. ${ }^{4}$ Estudos comprovaram que as proteases produzem melhores resultados retendo o valor nutricional dos alimentos, ${ }^{5}$ porém a qualidade do produto varia com a natureza da enzima e as condições de processamento. ${ }^{6}$

A hidrólise de proteínas pode ser realizada com enzimas, ácidos ou álcalis, mas a hidrólise enzimática é mais indicada que métodos químicos rigorosos para a produção de hidrolisados com aplicações nutricionais. Adicionar enzimas ao invés de reagentes químicos oferece muitas vantagens porque permite o controle da hidrólise, melhorando as propriedades do produto final. Além disso, o processo de hidrólise enzimática é mais simples, eficiente e envolve condições alcalinas moderadas que não destroem as proteínas recuperadas por racemização e outras reações químicas. ${ }^{7}$

A alcalase é uma enzima produzida por fermentação submersa do microrganismo Bacillus licheniformis e foi desenvolvida pela Novo Nordisk (Bagsvaerd, Denmark) para a indústria de detergentes. Temse provado repetidamente, por muitos pesquisadores, que é a melhor enzima usada na preparação de diversos hidrolisados protéicos. ${ }^{8}$ A flavourzyme é uma protease fúngica complexa produzida pela fermentação submersa de uma linhagem selecionada de Aspergillus oryzae que não foi geneticamente modificada, atuando na hidrólise sob condições neutras ou ligeiramente ácidas. ${ }^{9}$

As proteínas hidrolisadas vem sendo utilizadas há varias décadas para administração nutricional em indivíduos que não podem

\footnotetext{
*e-mail: mysame@yahoo.com
}

digerir a proteína intacta. ${ }^{10}$ Os hidrolisados protéicos são produzidos e aplicados na indústria de alimentos incluindo substitutos lácteos, suplementos protéicos, estabilizadores de bebidas, realçadores de sabor e produtos de confeitaria. ${ }^{11}$

Existe ampla divulgação cientifica sobre hidrolisados de pescado e outras matérias primas, ${ }^{8-18}$ no entanto, é escassa em relação às proteínas de frango. Como o Brasil tornou-se um dos principais produtores de carne de frango, com uma produção anual de aproximadamente 10 milhões de toneladas, o estudo do comportamento de enzimas proteolíticas sobre as proteínas desta matéria prima contribuirá com o conhecimento necessário para promover novas tecnologias aplicadas tanto a cortes nobres como a resíduos da industrialização, com a finalidade de obter novos produtos com diferentes propriedades funcionais e usos na indústria de alimentos.

O objetivo deste trabalho foi a obtenção de hidrolisados enzimáticos de carne de frango utilizando enzimas proteolíticas, avaliando-se a influência das variáveis da hidrólise enzimática: concentração de substrato [S], concentração de enzima [E] e tempo de hidrólise sobre o grau de hidrólise das proteínas.

\section{PARTE EXPERIMENTAL}

\section{Matéria prima}

As matérias primas utilizadas para a obtenção dos hidrolisados protéicos foram peito e coxa de frango sem pele e sem osso, obtidos do comércio local da cidade do Rio Grande (RS). A carne dos diferentes cortes foi triturada em um processador homogeneizador (Walita Mega Máster Plus), acondicionada em sacos plásticos e estocada em freezer comum a $-18^{\circ} \mathrm{C}$.

\section{Enzimas}

As enzimas utilizadas no processo foram a Alcalase $2.4 \mathrm{~L}^{\circledR} \mathrm{e}$ a Flavourzyme $1000 \mathrm{~L}^{\circledR}$, fornecidas pela Novozymes Latina Americana Ltda. A Alcalase 2.4L ${ }^{\circledR}$ é uma endopeptidase de Bacillus licheniformis, com substilisina Carlsberg como seu principal componente, possuindo atividade específica de 2.4 Unidades Anson (AU) por grama. Uma Unidade Anson (AU) equivale a um miliequivalente de tirosina liberada da hidrólise de hemoglobina por minuto. A Flavourzyme 1000L ${ }^{\circledR}$ 
é uma exopeptidase com uma atividade de 1 LAPU/g. Uma LAPU (Unidade Leucina Aminopeptidase) é a quantidade de enzima que hidrolisa $1 \mu \mathrm{mol}$ de leucina- $\rho$-nitroanilida por minuto.

\section{Composição centesimal}

Os dois cortes de carne de frango, peito e coxa, tiveram sua composição centesimal determinada de acordo com a metodologia recomendada pela AOAC. ${ }^{19}$ A quantidade de proteína presente em cada corte foi determinada pelo método de determinação de nitrogênio total, Kjeldahl (N x 6,25); lipídios pelo método gravimétrico de extração a quente de lipídios utilizando extrator de Soxhlet; cinzas pelo método gravimétrico em mufla $\left(550-600^{\circ} \mathrm{C}\right)$ e o teor de umidade pelo método gravimétrico em estufa $\left(105^{\circ} \mathrm{C}\right)$.

\section{Processo de hidrólise}

A Figura 1 mostra o fluxograma do processo hidrólise de carne de frango (peito e coxa). As reações enzimáticas foram conduzidas à temperatura e $\mathrm{pH}$ de máxima atividade catalítica de cada enzima de acordo com a literatura. ${ }^{9,13,14,20-25} \mathrm{O}$ substrato foi homogeneizado em uma solução tampão fosfato $0,2 \mathrm{M} \mathrm{e} \mathrm{o} \mathrm{pH} \mathrm{fixado} \mathrm{em} 7$ para a enzima flavourzyme e 7,5 para a enzima alcalase. Pesou-se uma determinada quantidade de carne de frango que correspondeu a uma concentração total de proteína em solução entre 3,3 e $11,7 \%(\mathrm{~m} / \mathrm{v})$. As reações enzimáticas foram realizadas em reator de vidro de parede dupla conectado a um banho termostatizado, mantendo a temperatura fixa a 50 e $55^{\circ} \mathrm{C}$ para as reações com as enzimas flavourzyme e alcalase, respectivamente. As enzimas foram adicionadas ao meio variando-se sua concentração em relação à massa total de proteínas de 2,9 a 9,1\% ( $\mathrm{g}$ de enzima/g proteína de carne).

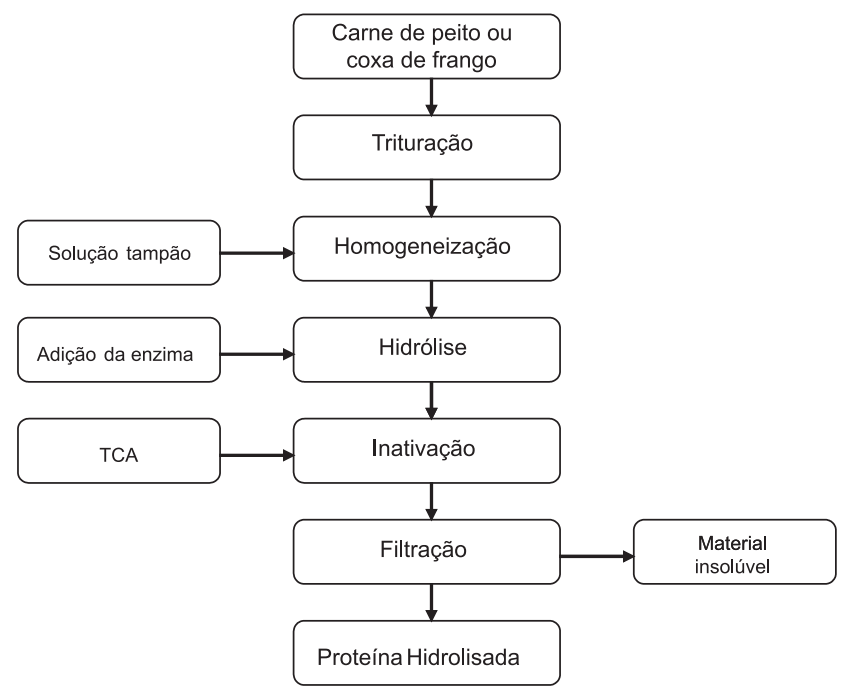

Figura 1. Fluxograma do processo de hidrólise enzimática das proteínas da carne de frango

\section{Determinação do grau de hidrólise (GH)}

Transcorrido o tempo de hidrólise que variou de 39,6 a 140,4 min, alíquotas de $1 \mathrm{~mL}$ de hidrolisado foram inativadas pela adição de 9 mL de solução de ácido tricloroacético (TCA) 6,25\% e deixadas em repouso por 10 min. Após filtração em papel Whatman $n^{\circ} 40$, para remoção do material insolúvel precipitado pelo TCA, determinou- se o teor de proteínas solúveis no filtrado utilizando o método de Folin-Lowry, ${ }^{26}$ expresso em mg de albumina. O grau de hidrólise (GH) foi estimado segundo o método descrito por Hoyle e Marrit ${ }^{27} \mathrm{e}$ por Baek e Cadwallader ${ }^{18}$ com modificações, sendo expresso como a porcentagem de proteínas solúveis no TCA em relação à quantidade de proteína inicial total, e calculado segundo a Equação (1):

$\% \mathrm{GH}=\frac{\left(\mathrm{PS}_{\text {tempot }}-\mathrm{PS}_{\text {tempo } 0}\right) \times 100}{\mathrm{P}_{\text {total }}}$

onde o branco, $\mathrm{PS}_{\text {tempo } 0}$, correspondeu à quantidade de proteína solúvel em TCA 6,25\% antes da adição da enzima; PS $_{\text {tempo }}$ foi a quantidade de proteína solúvel em determinado tempo após a adição da enzima e $\mathrm{P}_{\text {total }}$ foi a quantidade de proteína total na amostra determinada por micro Kjeldahl (N x 6,25).

\section{Planejamento experimental}

Com a finalidade de avaliar a influência das concentrações de substrato e de enzima e do tempo no processo de hidrólise, realizou-se um planejamento experimental fatorial completo $2^{3}$, com três repetições do ponto central, considerando como variável dependente o grau de hidrólise das proteínas. A Tabela 1 apresenta os níveis e valores das variáveis independentes utilizadas no planejamento experimental. Os níveis estudados para as variáveis independentes foram baseados em condições trabalhadas por diferentes pesquisadores. ${ }^{28-31}$

Tabela 1. Níveis e valores das variáveis independentes de concentração de substrato, de concentração de enzima e de tempo utilizados no planejamento experimental fatorial completo $2^{3}(\alpha=1,68)$

\begin{tabular}{lccccc}
\hline $\begin{array}{l}\text { Variáveis indepen- } \\
\text { dentes }\end{array}$ & $-\alpha$ & -1 & 0 & 1 & $+\alpha$ \\
\hline $\begin{array}{l}\text { concentração de sub- } \\
\text { strato [S] (\%p/v) }\end{array}$ & $-3,3$ & 5,0 & 7,5 & 10,0 & 11,7 \\
$\begin{array}{l}\text { concentração de } \\
\text { enzima [E] (\%p/p) }\end{array}$ & 2,9 & 4,0 & 6,0 & 8,0 & 9,1 \\
\begin{tabular}{l} 
tempo (min) \\
\hline
\end{tabular} & 39,6 & 60,0 & 90,0 & 120,0 & 140,4 \\
\hline
\end{tabular}

A influência da concentração de substrato, da concentração de enzima e do tempo sobre o grau de hidrólise foi avaliada estatisticamente, submetendo-se os resultados obtidos à análise de efeitos e verificação dos modelos empíricos através dos coeficientes de regressão e análise de variância (ANOVA).

\section{RESULTADOS E DISCUSSÃO}

\section{Composição proximal da carne de frango}

Dependendo do corte, a carne de frango apresentou composição diferente, como se pode observar na Tabela 2, onde o teor de umidade, lipídios e cinzas são maiores na coxa do que no peito de frango, apresentando a proteína uma relação inversa, maior teor no peito do que na coxa. A porcentagem de proteínas de cada corte foi utilizada para calcular a quantidade de carne necessária para obter as suspensões de cada ensaio de hidrólise enzimática. Os valores encontrados de composição centesimal para os diferentes cortes de frango correspondem a valores encontrados na literatura. ${ }^{33}$ 
Tabela 2. Composição centesimal* de peito e coxa de frango** em base úmida e base seca

\begin{tabular}{|c|c|c|c|c|}
\hline \multirow[t]{2}{*}{ Componente (\%) } & \multicolumn{2}{|c|}{ Peito } & \multicolumn{2}{|c|}{ Coxa } \\
\hline & bu & bs & $\mathrm{bu}$ & bs \\
\hline Umidade & $74,98 \pm 0,14$ & - & $77,56 \pm 0,62$ & - \\
\hline Proteína & $22,36 \pm 0,57$ & $93,48 \pm 1,92$ & $16,82 \pm 0,06$ & $80,62 \pm 3,75$ \\
\hline Lipídios & $0,77 \pm 0,29$ & $3,17 \pm 1,05$ & $3,34 \pm 0,86$ & $15,86 \pm 3,38$ \\
\hline Cinzas & $0,81 \pm 0,25$ & $3,34 \pm 0,87$ & $0,90 \pm 0,12$ & $4,27 \pm 0,36$ \\
\hline
\end{tabular}

b.u = base úmida; b.s = base seca. * Resultado expresso como média e desvio padrão de três determinações. ** Sem pele e sem osso.

Tabela 3. Valores de grau de hidrólise utilizando peito e coxa de frango como substrato nos ensaios com as enzimas alcalase e flavourzyme

\begin{tabular}{|c|c|c|c|c|c|c|c|}
\hline \multirow{3}{*}{ ensaio } & \multirow{3}{*}[\mathrm{S}]{$(\% \mathrm{p} / \mathrm{v})$} & \multirow{3}{*}[\mathrm{E}]{$(\% \mathrm{p} / \mathrm{p})$} & \multirow{3}{*}{$\mathrm{t}(\min )$} & \multicolumn{4}{|c|}{$\mathrm{GH}(\%)$} \\
\hline & & & & \multicolumn{2}{|c|}{ Alcalase } & \multicolumn{2}{|c|}{ Flavourzyme } \\
\hline & & & & Peito & Coxa & Peito & Coxa \\
\hline 1 & $-1(5)$ & $-1(4)$ & $-1(60)$ & 34,44 & 33,98 & 23,77 & 12,32 \\
\hline 2 & $1(10)$ & $-1(4)$ & $-1(60)$ & 24,32 & 18,62 & 17,22 & 8,30 \\
\hline 3 & $-1(5)$ & $1(8)$ & $-1(60)$ & 45,22 & 36,36 & 22,78 & 20,81 \\
\hline 4 & $1(10)$ & $1(8)$ & $-1(60)$ & 25,61 & 19,35 & 22,23 & 16,98 \\
\hline 5 & $-1(5)$ & $-1(4)$ & $1(120)$ & 35,80 & 37,48 & 25,68 & 14,52 \\
\hline 6 & $1(10)$ & $-1(4)$ & $1(120)$ & 23,96 & 23,74 & 19,46 & 10,32 \\
\hline 7 & $-1(5)$ & $1(8)$ & $1(120)$ & 47,27 & 38,79 & 27,29 & 22,54 \\
\hline 8 & $1(10)$ & $1(8)$ & $1(120)$ & 25,92 & 25,71 & 26,15 & 19,23 \\
\hline 9 & $-1,68(3,3)$ & $0(6)$ & $0(90)$ & 57,42 & 38,44 & 40,47 & 20,28 \\
\hline 10 & $1,68(11,7)$ & $0(6)$ & $0(90)$ & 20,93 & 19,61 & 20,94 & 14,39 \\
\hline 11 & $0(7,5)$ & $-1,68(2,9)$ & $0(90)$ & 29,20 & 29,78 & 21,38 & 11,89 \\
\hline 12 & $0(7,5)$ & $1,68(9,1)$ & $0(90)$ & 29,98 & 29,82 & 26,83 & 18,34 \\
\hline 13 & $0(7,5)$ & $0(6)$ & $-1,68(39,6)$ & 26,27 & 26,34 & 21,32 & 14,63 \\
\hline 14 & $0(7,5)$ & $0(6)$ & $1,68(140,4)$ & 32,26 & 33,50 & 28,07 & 20,46 \\
\hline 15 & $0(7,5)$ & $0(6)$ & $0(90)$ & 33,40 & 28,99 & 24,27 & 17,71 \\
\hline 16 & $0(7,5)$ & $0(6)$ & $0(90)$ & 33,04 & 30,70 & 25,16 & 17,17 \\
\hline 17 & $0(7,5)$ & $0(6)$ & $0(90)$ & 32,86 & 29,98 & 25,64 & 18,14 \\
\hline
\end{tabular}

$[\mathrm{S}]=$ concentração de substrato; $[\mathrm{E}]=$ concentração de enzima; $\mathrm{t}=$ tempo; $\mathrm{GH}$ = grau de hidrólise .

\section{Grau de hidrólise dos hidrolisados de peito e coxa de frango obtidos com alcalase e flavourzyme}

Os valores obtidos de grau de hidrólise com alcalase e flavourzyme utilizando peito e coxa de frango como substrato estão apresentados na Tabela 3. O GH apresentou uma variação de 20,93 a 57,42\% quando foi utilizado peito de frango, e de 18,62 a $38,79 \%$ quando se utilizou coxa de frango como substrato para alcalase. Os valores de GH obtidos com flavourzyme em peito de frango variaram de 17,22 a $40,47 \%$ e de 8,30 a $22,54 \%$ em coxa de frango.

Constatamos que quando se utilizou coxa de frango como substrato obtiveram-se, na maioria dos ensaios com alcalase, valores menores de GH quando comparados com os hidrolisados de peito. Já para flavourzyme, todos os ensaios realizados com coxa de frango apresentaram valores menores de $\mathrm{GH}$ do que com peito de frango, verificando-se uma diferença bem mais acentuada do que a observada nos ensaios com alcalase. Este comportamento do GH em relação à matéria prima pode ser devido ao maior teor de lipídeos presente na coxa do que no peito, o que dificultaria a ação da enzima sobre as proteínas. Slyzyte et al. ${ }^{9}$ analisaram a composição de diferentes frações obtidas após a hidrólise de bacalhau (Gadus morhua) com as enzimas flavourzyme e neutrase e observaram que uma matéria prima contendo elevada quantidade de lipídios resultava em um hidrolisado com menor quantidade de proteína solubilizada. Estes autores também relataram que a quantidade de lipídios na matéria prima influencia o processo de hidrólise, devido a que uma quantidade relativamente alta poderia formar complexos proteína/lipídeo, que pareceriam ser mais resistentes à quebra enzimática. 
A diferença ocasionada pelo tipo de substrato também pode estar relacionada com o conteúdo de colágeno presente em maior quantidade na coxa do que no peito. Conforme determinado por Nowsad et al., ${ }^{32}$ o teor de colágeno em coxas de frango foi de $9,3 \%$ podendo chegar a 14,7\% em animais velhos, enquanto que para peito de frango estes valores foram menores, em torno de 3,9e 4,9\%. Segundo Gildberg, ${ }^{34}$ a enzima alcalase possui alguma atividade proteolítica sobre o colágeno, o que justifica a menor diferença encontrada nos valores de $\mathrm{GH}$ em relação à flavourzyme em peito e coxa de frango.

Valores semelhantes de $\mathrm{GH}$ aos encontrados neste trabalho foram reportados por Centenaro, ${ }^{28}$ que obteve valores de GH entre 12,2 e $43,7 \%$ utilizando a enzima alcalase sobre corvina (Micropogonias furnieri), em condições semelhantes a este estudo, variando a concentração de substrato de 3 a $7 \%$, e a concentração de enzima de 4 a $8 \%$ com um tempo de hidrólise de $1 \mathrm{~h}$. Liceaga-Gesualdo e Li-Chan ${ }^{35}$ obtiveram valores de $\mathrm{GH}$ acima de $35 \%$ com a enzima alcalase em 60 min de hidrólise das proteínas de arenque (Clupea harengus). Shahid et al. ${ }^{36}$ produziram proteína hidrolisada de capelin (Mallotus villosus), obtendo valores de $\mathrm{GH}$ acima de $20 \%$ em 120 min de hidrólise com a enzima alcalase. Cândido e Sgarbieri ${ }^{13}$ hidrolisaram as proteínas de tilápia do Nilo (Oreochromus niloticus) com a enzima flavourzyme em pH 7 a $50{ }^{\circ} \mathrm{C}, 12 \%$ de concentração de substrato e $1 \%$ de concentração de enzima, obtendo valores de GH na faixa de 2,5 a $45 \%$.

\section{Análise dos efeitos principais da [S], da [E] e do tempo e suas interações sobre o GH dos hidrolisados de peito e coxa de frango obtidos com alcalase e flavourzyme}

O tratamento estatístico dos dados obtidos permitiu a análise dos efeitos dos fatores [S], [E] e tempo de hidrólise, assim como suas interações no grau de hidrólise para um nível de confiança de $95 \%$. A Tabela 4 apresenta os efeitos obtidos das variáveis estudadas no GH das proteínas de peito e coxa de frango, utilizando as enzimas alcalase e flavourzyme.

Na Tabela 4 pode-se observar que todas as variáveis estudadas e suas interações apresentaram uma influência significativa no GH das proteínas de peito de frango utilizando-se alcalase. Quando se utilizou flavouryme neste mesmo substrato, as variáveis principais também apresentaram uma influência significativa, mas somente a interação da concentração de substrato com a concentração de enzima foi significativa. Para a hidrólise das proteínas da coxa de frango, somente as variáveis principais apresentaram uma influência significativa nas faixas estudas no processo, sendo que a concentração de enzima não apresentou um efeito significativo na hidrólise de coxa de frango com alcalase.
Tanto na hidrólise de peito como na de coxa de frango com alcalase, a concentração de substrato demonstrou ser a variável com maior influência no processo hidrolítico, apresentando um efeito negativo em ambos os casos, ou seja, quando a [S] no meio passou de 5 para $10 \%$, ocorreu uma diminuição no valor do GH de 17,15 e 13,31\% em peito e coxa de frango, respectivamente. Na hidrólise das proteínas com flavourzyme a [S] também apresentou um efeito negativo com ambos os substratos, sendo a variável de maior influência na hidrólise das proteínas de peito de frango, ocasionando uma diminuição no valor do $\mathrm{GH}$ de $6,93 \%$, quando se elevou a concentração de substrato no meio de 5 para $10 \%$.

Centenaro $^{28}$ e Santos ${ }^{29}$ também verificaram um efeito negativo para a concentração de substrato no GH das proteínas de pescado. Comportamento semelhante foi descrito por Kristinsson e Rasco ${ }^{8}$ que, em uma revisão detalhada sobre proteína hidrolisada de pescado, relataram que a concentração de substrato apresentava um efeito negativo na hidrólise das proteínas.

No presente trabalho, elevadas concentrações de substrato mostraram um efeito inibidor na hidrólise das proteínas. Este tipo de inibição causada pela elevada concentração de substrato, conforme Whitaker, ${ }^{37}$ citado por Tardioli, ${ }^{38}$ comporta-se como uma inibição acompetitiva, pois uma segunda molécula de substrato se liga em um local próximo ao sítio ativo da enzima, reduzindo a velocidade inicial de reação, impedindo que a primeira molécula se ligue corretamente ao sítio ativo ou que ela seja transformada em produto.

A concentração de enzima apresentou um efeito positivo em ambos os casos, sendo a variável de maior influência no GH das proteínas da coxa de frango com flavourzyme. Esta relação positiva de $[\mathrm{E}]$ com o grau de hidrólise era esperada, porém pretendia-se verificar se esta variável apresentaria um aumento significativo na faixa de concentração estudada, já que o aumento da concentração de enzima resultará em maior cisão das cadeias protéicas, aumentando a quantidade de proteínas de menor tamanho molecular e também o GH do produto obtido. Kristinsson e Rasco ${ }^{8}$ e Surówaka e Fik ${ }^{39}$ relataram que o aumento da concentração de protease acarreta um aumento na extensão da hidrólise.

Além do aumento da concentração de enzima, outra variável que aumentará o GH é o tempo de reação. Se não houver inibição pelo produto, o aumento da concentração de enzima somente acelerará a reação, mas se chegará ao mesmo GH com uma concentração mais baixa. Com o aumento do tempo de reação enzimática houve um acréscimo do $\mathrm{GH}$, apresentando esta variável um efeito positivo e significativo na variável resposta, para ambas as enzimas. Este resultado concorda com o apresentado por Liceaga-Gesualdo e Li-Chan ${ }^{35}$ que observaram uma hidrólise rápida de carne de arenque (Clupea harengus), atingindo um $\mathrm{GH}$ de $24 \%$

Tabela 4. Efeitos da concentração de substrato, da concentração de enzima, do tempo e de suas interações no grau de hidrólise das proteínas de peito e coxa de frango utilizando as enzimas alcalase e flavourzyme

\begin{tabular}{lcccccccc}
\hline \multirow{2}{*}{ Variáveis } & \multicolumn{2}{c}{ Peito } & \multicolumn{2}{c}{ Alcalase } & \multicolumn{2}{c}{ Peito } & \multicolumn{2}{c}{ Flavourzyme } \\
& Efeitos & valor $\mathrm{p}$ & Efeitos & valor $\mathrm{p}$ & Efeitos & valor $\mathrm{p}$ & Efeitos & valor $\mathrm{p}$ \\
\hline$[\mathrm{S}]$ & $-17,15$ & 0,0001 & $-13,31$ & 0,0012 & $-6,93$ & 0,0029 & $-3,70$ & 0,0050 \\
{$[\mathrm{E}]$} & 2,88 & 0,0027 & 0,94 & 0,1791 & 3,15 & 0,0139 & 6,58 & 0,0016 \\
$\mathrm{t}$ & 3,02 & 0,0024 & 4,31 & 0,0114 & 3,51 & 0,0113 & 2,64 & 0,0098 \\
{$[\mathrm{~S}] \mathrm{x}[\mathrm{E}]$} & $-6,54$ & 0,0009 & $-0,25$ & 0,7242 & 2,77 & 0,0299 & 0,27 & 0,5151 \\
{$[\mathrm{~S}] \mathrm{xt}$} & 0,93 & 0,0411 & 1,39 & 0,1497 & $-0,06$ & 0,9079 & 0,09 & 0,8227 \\
{$[\mathrm{E}] \mathrm{xt}$} & $-1,46$ & 0,0174 & 0,04 & 0,9490 & 1,07 & 0,1609 & $-0,06$ & 0,8762 \\
\hline
\end{tabular}

$[S]=$ concentração de substrato; $[\mathrm{E}]=$ concentração de enzima; $\mathrm{t}=$ tempo. 
em 20 min de incubação com a enzima alcalase, a pH 8,0 e $50^{\circ} \mathrm{C}$, sendo que após 60 min de hidrólise se obtinha um GH de $36 \%$.

Soares et al..$^{40}$ avaliaram a influência de diversas proteases comerciais na solubilização hidrolítica de carne de frango mecanicamente separada, e observaram que a solubilização das proteínas cessava após $3 \mathrm{~h}$ de proteólise nas condições estudadas. Cândido e Sgarbieri, ${ }^{13}$ após testarem diferentes enzimas, escolheram a flavourzyme para hidrolisar as proteínas miofibrilares de tilápia do Nilo (Oreochromus niloticus). Eles observaram que a taxa de hidrólise era elevada nos primeiros 30 min, mas decaia significantemente após este tempo de incubação. Os autores concluíram que esta queda na taxa de hidrólise poderia ser explicada pelos seguintes fenômenos: diminuição de peptídeos disponíveis para hidrólise; possível inibição enzimática pelos produtos formados da reação ou pela parcial desnaturação da enzima.

Em relação às interações das variáveis estudadas no processo, todas foram significativas para a hidrólise de peito de frango com alcalase. Ou seja, quando duas variáveis simultaneamente foram consideradas passando do nível inferior para o superior, verificou-se uma interação significativa no valor do $\mathrm{GH}$ das proteínas de peito de frango. A interação da [S] com o tempo apresentou um efeito positivo no GH. As interações da $[\mathrm{S}]$ com a $[\mathrm{E}]$ e de $[\mathrm{E}]$ com o tempo apresentaram um efeito negativo no $\mathrm{GH}$ das proteínas. $\mathrm{Na}$ hidrólise de peito de frango com flavourzyme, somente a interação da $[\mathrm{S}]$ com a [E] apresentou uma interação significativa no valor de GH. Nos hidrolisados de coxa de frango não se verificou efeito estatisticamente significativo da interação das variáveis em estudo, para ambas as enzimas.

\section{Verificação de modelos matemáticos empíricos para o GH dos hidrolisados de peito e coxa de frango obtidos com alcalase e flavourzyme}

Para verificação do modelo matemático realizou-se uma análise de variância (Tabela 5) com os valores de GH das proteínas de peito e coxa de frango, obtidos com ambas as enzimas, considerando-se somente as variáveis significativas.
De acordo com a literatura, ${ }^{41}$ um modelo tem significação estatística quando o valor de $\mathrm{F}$ calculado é pelo menos 3 a 5 vezes maior do que o tabelado. Através da análise de variância, obtiveram-se modelos preditivos para o grau de hidrólise das proteínas de peito e coxa de frango com alcalase e de coxa de frango com flavourzyme, podendo-se afirmar que os modelos são confiáveis para predizer o GH de qualquer combinação das variáveis independentes nos níveis estudados. Apenas os valores de GH obtidos a partir da hidrólise de peito de frango com flavourzyme não apresentaram modelo preditivo relacionando as variáveis estudadas, visto que o valor de F calculado não foi suficientemente maior do que o tabelado. A Tabela 6 apresenta as equações para os modelos matemáticos obtidos a partir dos valores de GH das proteínas de peito e coxa de frango com alcalase e de coxa de frango com flavourzyme. Os elevados valores de coeficiente de determinação, obtidos para estes modelos, demonstram que acima de 90\% do comportamento do GH pode ser explicado por eles. Portanto, foi possível construir as superfícies de resposta (Figura 2) a partir dos modelos obtidos.

Observa-se na Figura 2.a que os maiores valores de GH das proteínas de peito de frango com alcalase foram obtidos em concentrações de enzima entre 6 e $9 \%$ e tempos de hidrólise entre 80 e 120 min. A hidrólise de coxa de frango com alcalase (Figura 2b) gerou valores maiores de $\mathrm{GH}$ em baixas concentrações de substrato e elevados tempos de hidrólise. Para a hidrólise das proteínas de coxa de frango com flavourzyme (Figura 2c), constatou-se que elevados valores de $\mathrm{GH}$ foram obtidos em baixas concentrações de substrato, em torno de $3,3 \%$, e em concentrações de enzima entre 7 e $9 \%$.

Estudos comparativos entre enzimas exógenas como a alcalase e a flavourzyme são difíceis, devido a estas enzimas possuírem diferenças em atividade especifica e em especificidade, assim como condições ótimas de $\mathrm{pH}$ e temperatura também diferentes. De acordo com Smyth e Fitzgerald, ${ }^{25}$ a especificidade da atividade enzimática em preparados de enzimas comerciais não está bem caracterizada. Estes autores avaliaram a atividade de preparados enzimáticos utilizando diferentes substratos fluorogênicos sintéticos e observaram que a flavourzyme apresentava a maior atividade aminopeptidase,

Tabela 5. Análise de variância dos valores de grau de hidrólise dos hidrolisados de peito e coxa de frango obtidos com alcalase e flavourzyme a um nível de confiança de $95 \%$

\begin{tabular}{|c|c|c|c|c|c|c|}
\hline Resposta & $\begin{array}{l}\text { Fonte de } \\
\text { Variação }\end{array}$ & $\begin{array}{l}\text { Graus de } \\
\text { Liberdade }\end{array}$ & $\begin{array}{c}\text { Soma dos } \\
\text { Quadrados }\end{array}$ & $\begin{array}{l}\text { Média dos } \\
\text { Quadrados }\end{array}$ & $\begin{array}{l}\text { Valor de F } \\
\text { Calculado }\end{array}$ & $\begin{array}{c}\text { Valor de F } \\
\text { Tabelado }\end{array}$ \\
\hline \multirow[t]{3}{*}{$\mathrm{GH}_{1}(\%)$} & Regressão & 8 & 1370,27 & 171,28 & & \\
\hline & Resíduos & 8 & 65,22 & 8,15 & 21,01 & 3,44 \\
\hline & Total & 16 & 1435,49 & & & \\
\hline \multirow[t]{3}{*}{$\mathrm{GH}_{2}(\%)$} & Regressão & 2 & 667,90 & 333,95 & & \\
\hline & Resíduos & 14 & 23,76 & 1,70 & 196,44 & 3,74 \\
\hline & Total & 16 & 691,66 & & & \\
\hline \multirow[t]{3}{*}{$\mathrm{GH}_{3}(\%)$} & Regressão & 7 & 307,17 & 43,88 & & \\
\hline & Resíduos & 9 & 101,59 & 11,29 & 3,94 & 3,29 \\
\hline & Total & 16 & 408,77 & & & \\
\hline \multirow[t]{3}{*}{$\mathrm{GH}_{4}(\%)$} & Regressão & 4 & 230,94 & 57,73 & & \\
\hline & Resíduos & 12 & 25,26 & 2,10 & 27,49 & 3,26 \\
\hline & Total & 16 & 256,20 & & & \\
\hline
\end{tabular}

$\mathrm{GH}_{1}=$ grau de hidrólise com alcalase em peito de frango; $\mathrm{GH}_{2}=$ grau de hidrólise com alcalase em coxa de frango; $\mathrm{GH}_{3}=$ grau de hidrólise com flavourzyme em coxa de frango; $\mathrm{GH}_{4}=$ grau de hidrólise com flavourzyme em peito de frango. 
Tabela 6. Equações obtidas para os modelos matemáticos obtidos a partir dos valores de grau de hidrólise de hidrolisados de peito e coxa de frango com alcalase e de coxa de frango com flavourzyme

\begin{tabular}{llc}
\hline Resposta & Equação obtida para o modelo preditivo a 95\% de confiança & $\mathrm{R}^{2}$ \\
\hline $\mathrm{GH}_{1}(\%)$ & $=33,09-9,10 *[\mathrm{~S}]+2,19 *[\mathrm{~S}]^{2}+1,97 *[\mathrm{E}]-1,20 *[\mathrm{E}]^{2}+0,98 * \mathrm{t}-1,32 * \mathrm{t}^{2}-2,37 *[\mathrm{~S}]^{*}[\mathrm{E}]-0,43 *[\mathrm{~S}]^{* \mathrm{t}}$ & 0,9545 \\
$\mathrm{GH}_{2}(\%)$ & $=29,48-6,66 *[\mathrm{~S}]+2,16 * \mathrm{t}$ & 0,9655 \\
$\mathrm{GH}_{4}(\%)$ & $=17,15-1,85 *[\mathrm{~S}]+3,29 *[\mathrm{E}]-0,99 *[\mathrm{E}]^{2}+1,32 * \mathrm{t}$ & 0,9015 \\
\hline
\end{tabular}

$\mathrm{GH}_{1}=$ grau de hidrólise com a enzima alcalase em peito de frango; $\mathrm{GH}_{2}=$ grau de hidrólise com a enzima alcalase em coxa de frango; $\mathrm{GH}_{4}=$ grau de hidrólise com a enzima flavourzyme em peito de frango; $[\mathrm{S}]=$ concentração de substrato; $[\mathrm{E}]=$ concentração de enzima; $\mathrm{t}=$ tempo de hidrólise e $\mathrm{R}^{2}=$ coeficiente de determinação.

apresentando também certa atividade endoproteinase; já a enzima alcalase apresentava a maior atividade endoproteinase.

A hidrólise enzimática das proteínas resulta em uma mistura de aminoácidos livres, di-, tri- e oligopeptídeos, aumenta o número de grupos polares e a solubilidade do hidrolisado e, portanto, modifica as características funcionais das proteínas, o que geral-
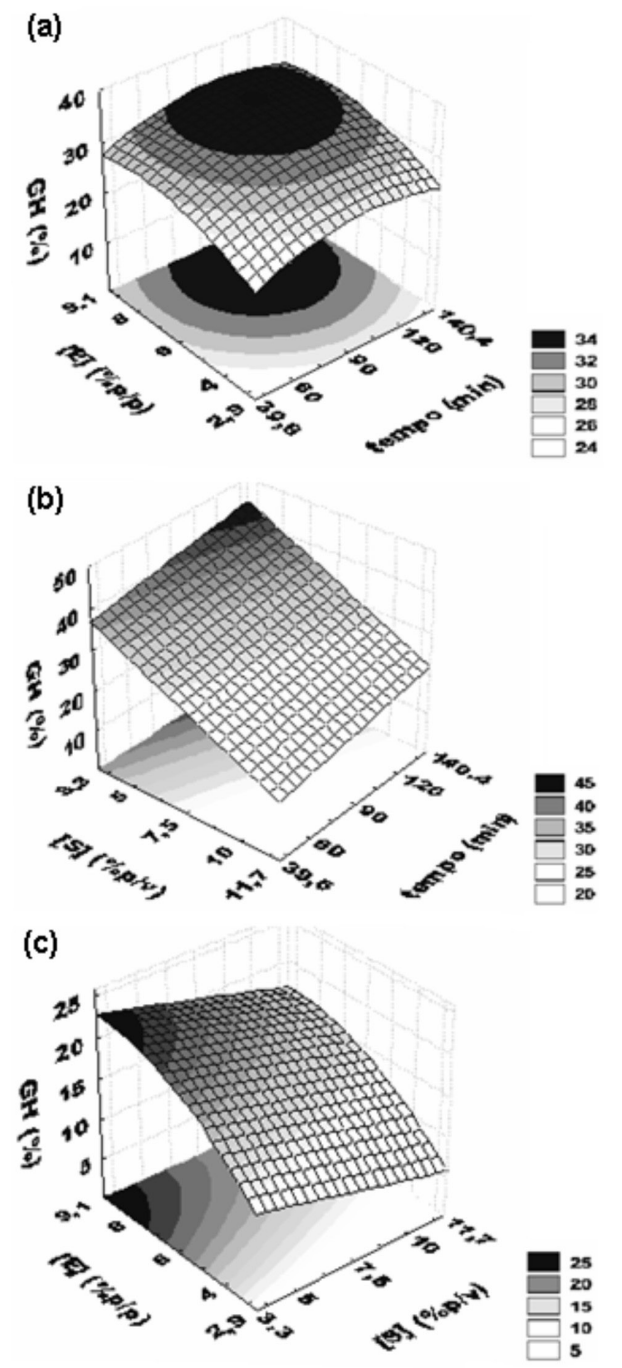

Figura 2. Superfícies de resposta que relacionam o grau de hidrólise (GH) das proteínas com: (a) a concentração de enzima [E] e o tempo em peito de frango com a enzima Alcalase; (b) a concentração de substrato [S] e o tempo em coxa de frango com a enzima Alcalase; (c) a concentração de substrato [S] e a concentração de enzima [E] em coxa de frango com a enzima Flavourzyme mente melhora a qualidade funcional. Como as enzimas alcalase e flavourzyme apresentam diferentes especificidades, hidrólises com estas enzimas irão produzir hidrolisados protéicos com diferentes perfis de peptídeos. Os hidrolisados obtidos com estas enzimas, mesmo possuindo valores semelhantes de $\mathrm{GH}$, poderão ter um perfil peptídico muito distinto.

Segundo Kristinsson e Rasco, ${ }^{8}$ o tamanho da proteína hidrolisada é o fator chave na determinação das propriedades funcionais dos hidrolisados. Embora a análise da distribuição de tamanho dos peptídios e de aminoácidos revele o perfil destes hidrolisados, o GH nos dá uma idéia do mensuramento da extensão da proteína clivada. Sendo assim, a alcalase que atua principalmente em ligações endopeptídicas, dependendo da extensão da hidrólise, irá produzir uma mistura de peptídios de baixa massa molecular. Como no presente estudo foram obtidos maiores valores de GH com esta enzima, melhores propriedades de solubilidade, capacidade de formação de espuma e também de digestibilidade serão apresentadas por estes hidrolisados, concordando com a literatura. ${ }^{8,13,15,17,23,25,28,31}$ Já a flavourzyme que possui atividade principalmente exopeptídica, liberará aminoácidos com grupo carboxi-terminal, portanto, os hidrolisados obtidos com esta enzima deverão conter um alto conteúdo de aminoácidos livres e, principalmente devido ao menor $\mathrm{GH}$, deverão conter peptídeos de alto peso molecular que irão determinar melhores propriedades de capacidade de retenção de água e óleo, de capacidade emulsificante e de estabilidade de espuma.

Certas propriedades funcionais dos hidrolisados protéicos exercem um papel predominante, pois irão determinar as características principais do produto final, definindo seu uso. Logo, o tipo e a forma da proteína a ser utilizada como ponto de partida do hidrolisado protéico, assim como a escolha da enzima e o GH obtido, devem ser controlados em função das principais propriedades funcionais que se deseja explorar. ${ }^{42}$

\section{CONCLUSÃO}

Obteve-se hidrolisados enzimáticos de peito e coxa de frango com diferentes valores de grau de hidrólise, maiores para os obtidos com a enzima alcalase quando comparados com os obtidos com flavourzyme. Maiores valores de grau de hidrólise foram obtidos com a carne de peito como substrato, quando comparados com a carne de coxa. A análise estatística dos resultados mostrou um efeito negativo da concentração de substrato e um efeito positivo da concentração de enzima e do tempo no grau de hidrólise das proteínas. Quando se utilizou peito de frango como substrato, a melhor condição de hidrólise para ambas as enzimas foi a de menor concentração de substrato $(3,3 \% \mathrm{~m} / \mathrm{v})$ e de concentração de enzima e tempo nos valores dos pontos centrais: $6 \%(\mathrm{~m} / \mathrm{m})$ e 90 min, respectivamente. Para a carne de coxa a condição de maior grau de hidrólise foi conseguida para uma concentração de substrato de 5\% $(\mathrm{m} / \mathrm{v})$, concentração de enzima de $8 \%(\mathrm{~m} / \mathrm{m})$ e um tempo de $120 \mathrm{~min}$ de hidrólise, para ambas as enzimas. A obtenção de hidrolisados com graus de hidrólise diferentes sugere sua aplicação como ingredientes alimentícios, dependendo da propriedade funcional desejada. 


\section{AGRADECIMENTOS}

À Comunidade Européia (projeto Chill-On) pelo suporte financeiro e à Capes pela concessão da bolsa de estudos.

\section{REFERÊNCIAS}

1. Bobbio, F. O.; Bobbio P. A.; Manual de Laboratório de Química de Alimentos, Livraria Varela: São Paulo, 1995.

2. Mullally, M. M.; O’Calaghan, D. M.; Fitzgerald, R. J.; Donnelly, W. J.; Dalton, J. P.; J. Agric. Food Chem. 1994, 42, 2973.

3. Gonzales-Tello, P.; Camacho, F.; Jurado, E.; Paez, M. P.; Guadiz, E. M.; Biotechnol. Bioeng. 1994, 44, 523.

4. Lahl, W. J.; Braun, S. D.; Food Technol. 1994, 58, 68.

5. Silva, P. M. E. M.; Mazzilli, R. N.; Cusin, F.; J. Food Comp. Anal. 1999, $12,219$.

6. Simpson, B. K.; Nayeri, G.; Yaylayan, V.; Ashie, I. N. A.; J. Food Chem. 1998, 61, 131

7. Fonkwe, L. G.; Singh, R. K.; Process Biochem. 2005, 31, 605.

8. Kristinsson, H. G.; Rasco, B. A.; Critical Rev. Food Sci. Nutr. 2000, 40, 43.

9. Slyzyte, R.; Dauksas, E.; Falch, E.; Storro, I.; Rustad, T.; Process Biochem. 2005, 40, 1415.

10. Mahmoud, M. I.; Malone, W. T.; Cordle, C. T.; J. Food Sci. 1992, 57, 1223.

11. Frokjaer, S.; J. Food Technol. 1994, 48, 68

12. Govindaraju, K.; Srinivas, H.; LWT--Food Sci. Technol. 2006, 39, 54.

13. Cândido, L. M. B.; Sgarbieri, V. C.; J. Sci. Food Agric. 2003, 83, 937.

14. Abdul-Hamid, A.; Bakar. J.; Bee, H. H.; J. Food Chem. 2002, 78, 69.

15. Hocková, M.; Runsáhová, M.; Zemanovic, J.; Czech. J. Food Sci. 2002, $20,7$.

16. Kristinsson, H. G.; Rasco, B. A.; Process Biochem. 2000, 36,131.

17. Diniz, E. M.; Martin, A. M.; LWT--Food Sci. Technol. 1997, $30,266$.

18. Baek, H. H.; Cadwallader. K. R.; J. Food Sci. 1995, 60, 929.

19. A.O.A.C. - Association of Official Analytical Chemists; Official Methods of Analysis, 16 ${ }^{\text {th }}$ ed., Horowitz: Washington D.C., 1995.

20. Dauksas, E.; Falch, E.; Slizyte, R.; Rustad, T.; Process Biochem. 2005, $40,2659$.
21. Claver, I. P.; Zhou, H.; J. Food Biochem. 2005, $29,13$.

22. Gbogouri, G. A.; Linder, M.; Fanni, J.; Parmentier, M.; Food Chem. Toxicol. 2004, 69, 615 .

23. Furlan, E. F.; Oetterer. M.; Rev. Ciênc. Tecnol. 2002, 10, 79.

24. Kilcawley, N. K.; Wilkinson, M. G.; Fox, P. F.; Enzyme Microb. Technol. 2002, 31, 310 .

25. Smyth, M.; Fitzgerald, R. J.; Int. Dairy J. 1998, 8, 819.

26. Plummer, D. T.; An Introduction to Practical Biochemistry, McGrawHill Book Company Limited: London, 1978.

27. Hoyle, N. T.; Merritt, J. H.; J. Food Sci. 1994, 59, 76.

28. Centenaro, G. S.; Dissertação de Mestrado, Fundação Universidade Federal do Rio Grande, Brasil, 2007.

29. Santos, S. D.; Dissertação de Mestrado, Fundação Universidade Federal do Rio Grande, Brasil, 2006.

30. Nilsang, S.; Lertsiri, S.; Suphantharika, M.; Aassavaning, A.; J. Food Eng. 2005, 70, 571.

31. Roman, J. A.; Sgarbieri, V. C.; Ciênc. Tecnol. Aliment. 2005, 25, 468.

32. Nowsad, A. A. K. M.; Kanoh, S.; Niwa, E.; Meat Sci. 1999, 54, 169.

33. Huallanco, M. B. A.; Dissertação de Mestrado, Universidade de São Paulo, Brasil, 2004.

34. Gildeberg, A.; Arnesen, J. A.; Carlehög, M.; Process Biochem. 2002, 38 , 475.

35. Liceaga-Gesualdo, A. M.; Li-Chan, E. C. Y.; J. Food Sci. 1999, 64, 1000 .

36. Shahid, F.; Han, X. Q.; Synowiecki, J.; Food Chem. 1995, 53, 285.

37. Whitaker, R.; Principles of Enzymology for Food Science, Marcel Decker: New York, 1994

38. Tardioli, P. W.; Tese de Doutorado, Universidade Federal de São Carlos, Brasil, 2003.

39. Surówka, K.; Fik, M.; Int. J. Food Sci. Technol. 1992, 27, 9.

40. Soares, L. H. B.; Marques, D. N.; Albuquerque, P. M. Ayub, M. A. Z.; Int. J. Food Sci. Technol. 2000, 6, 301.

41. Kalil, S.; Maugeri, F.; Rodrigues, M. I.; Process Biochem. 2000, 35, 539; Barros Neto, B. ; Scarminio, T. S.; Bruns, R. E.; Planejamento e Otimização de Experimentos, Editora da Unicamp: São Paulo, 1996.

42. Furtado, M. A. M.; Gomes, J. C.; Silva, C. A. S.; Ornellas, C. B.; Silvestre, M. P. C.; Ciênc. Agrotecnol. 2001, 25, 625. 